\title{
Can we estimate cytokine storm from initial computed tomography images of Coronavirus disease-2019 patients?
}

\author{
Ozturk $\mathrm{C}^{1}$, Gungor $\mathrm{O}^{1}$, Koc $\mathrm{F}^{2}$, Goktas $\mathrm{EF}^{2}$, Dereli $\mathrm{N}^{3}$, Corbacioglu $\mathrm{SK}^{4}$, Ramadan $\mathrm{SU}^{1}$ \\ 1st Department of Radiology, Kecioren Training and Research Hospital, Ankara, Turkey. \\ cnsozt@yahoo.com
}

\begin{abstract}
OBJECTIVES: The present study aims to investigate whether elementary lesions detected at the time of the diagnosis, their distribution characteristics, and CT scoring can be predictive of a cytokine storm.

BACKGROUND: CT might have a prognostic predictive value beyond its diagnostic value.

METHODS: Sixty-eight patients, 32 with cytokine storm and 36 without cytokine storm, were included in the study. Four different scoring methods were created according to elementary lesions, distribution and involvement rate. CT scores and demographic findings of the cases were compared in the cytokine storm and non-cytokine storm groups.

RESULTS: The mean age of patients was 57.72 (SD: 13.5) and 40 (58.8\%) of them were male. The cytokine storm was significantly more common among male patients and patients of older age $(p=0.04)$.

The AUC values of CT score 1, CT score 2, CT score 3, and CT score 4 were as follows; $0.772(95 \% \mathrm{Cl}$; 0.651-0.892), 0.766 (95\% Cl; 0.647-0.885), 0.758 (95\% Cl; 0.639-8.78), and 0.760 (95\% Cl; 0.640-0.881), respectively. All CT scores had better predictive values in males.

CONCLUSIONS: CT scoring at the time of admission can be used to predict cases that may develop cytokine storm later (Tab. 4, Fig. 2, Ref. 15). Text in PDF www.elis.sk KEY WORDS: cytokine storm, covid-19, pneumonia, CT scoring, elementary lesions, lesion distributions.
\end{abstract}

\section{Introduction}

The pneumonia epidemic reported in Wuhan, China in December 2019 spread rapidly and became a pandemic, and it was named Coronavirus disease-2019 (COVID-19) by the World Health Organization (WHO) in February 2020 (1). While majority of the cases have asymptomatic and mild presentation, up to $10 \%$ of infected persons require mechanical ventilation and receive treatment in intensive care units (1). In severe cases, it was observed that a cytokine storm developed along with multiple organ damage while organ damage was directly caused by the virus (2)

Cytokine storm is a state that is triggered in cases of infection, rheumatological disease, malignancy, and when acute respiratory distress syndrome (ARDS) and pneumonia develop as a result of a severe inflammatory response of the immune system (2). In Turkey, efforts are ongoing to standardize the diagnosis and treatment of COVID-19 pneumonia in accordance with the guidelines prepared by the Ministry of Health. According to the guidelines of the Turkish Ministry of Health, the state of cytokine storm is

\footnotetext{
${ }^{1}$ Department of Radiology, Kecioren Training and Research Hospital, Ankara, Turkey, ${ }^{2}$ Department of Infectious Diseases and Clinical Microbiology, Kecioren Training and Research Hospital, Ankara, Turkey, ${ }^{3}$ Department of Anesthesiology and Intensive Care Medicine, Kecioren Training and Research Hospital. Ankara, Turkey, and ${ }^{4}$ Department of Emergency Medicine, Kecioren Training and Research Hospital, Ankara, Turkey

Address for correspondence: C. Ozturk, MD, 1st Department of Radiology, Kecioren Training and Research Hospital, Ankara, Turkey. Phone: +90.5052690073, Fax: +90.3123569002
}

diagnosed in the presence of findings such as persistent fever, deterioration observed in liver function tests, hypofibrinogenemia or increase in triglyceride values, as well as increase in C-reactive protein (CRP), ferritin, D-dimer values, and/or ongoing gradual decrease in lymphocyte and platelet counts in consecutive tests performed.

Although the reverse transcription polymerase chain reaction (RT-PCR) test results are specific in the diagnosis of COVID-19, the false-negative rate is too high to be ignored $(3,4)$. Therefore, computed tomography (CT) examination at the time of diagnosis plays an important role in the diagnosis (5). Typical chest CT findings of COVID-19 pneumonia include bilateral ground glass opacities (GGO) and/or consolidations manifesting with predominantly round morphology and peripheral distribution (5). An increasing volume of new data has been reported showing that CT might have a prognostic predictive value beyond its diagnostic value $(6,7)$.

The present study aims to investigate whether elementary lesions detected at the time of diagnosis, their distribution characteristics, and CT scoring can be predictive of a cytokine storm that may develop in the course of the disease in cases diagnosed with COVID-19 pneumonia that do not present findings of cytokine storm or ARDS at the time of admission.

\section{Methods}

\section{Study type and design}

This retrospective prognostic monocentric study was initiated upon the ethics committee decision dated 10.6.2020/2119. 

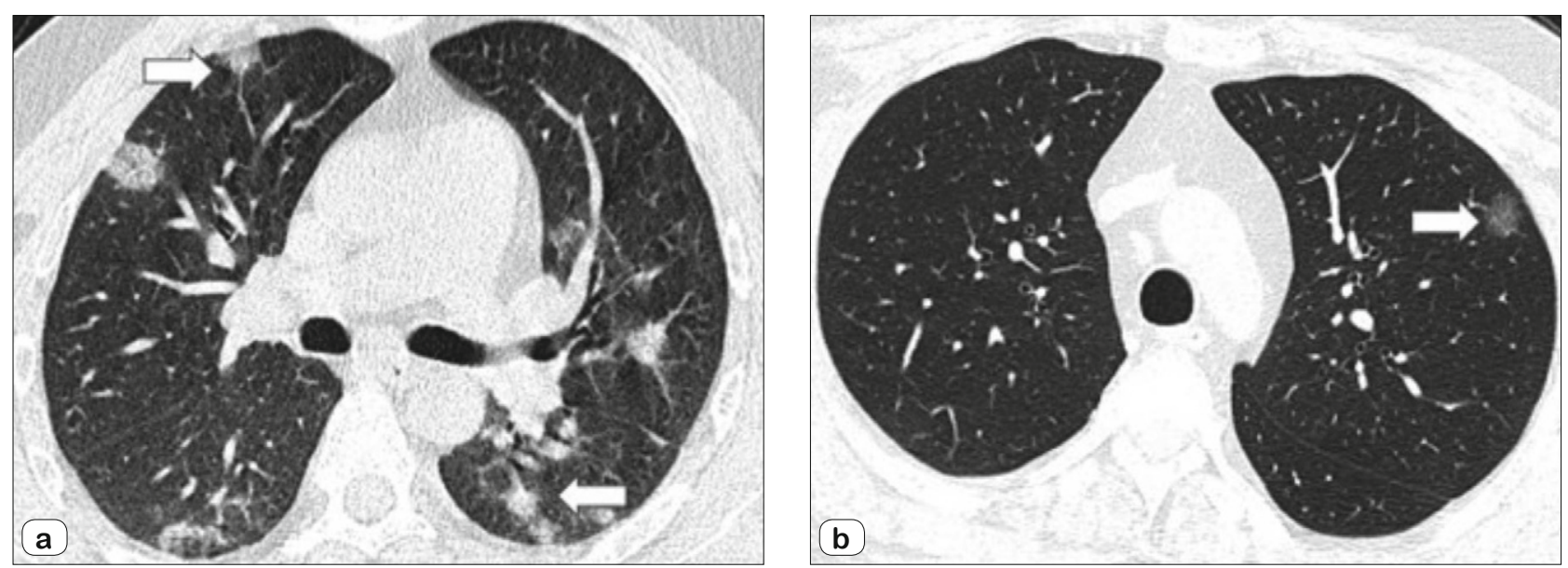

Fig. 1 a). Round consolidations located peripherally in the lung parenchyma window on axial chest CT (arrows) at the time of admission of a 42-year-old male patient who developed the cytokine storm during the treatment process (CT score 4: 8.4) b) A 43-year-old male patient, who had a peripherally located round ground glass opacity at the time of admission (arrow) (CT score 4: 0.4), and did not develop a cytokine storm during the treatment process,

\section{Study population and CT protocol}

The cases admitted to the pandemic clinic during March-August 2020 period were reviewed through the automation system of our hospital. Out of these cases, 3 researchers who were uninformed about CT findings, initially selected those who were developing a cytokine storm, were PCR-positive and had CT pneumonia at the time of admission. The latter patients were included in the group of cases with cytokine storm based on specified criteria (Fig. $1 \mathrm{~A}, \mathrm{~B}$ ). A control group (a group of patients with no cytokine storm observed) was formed by including a similar number of patients with clinically moderate and severe prognosis, whose characteristics observed in the same time period (EFG, FD, ND) were similar as to age and comorbidities to those of the patients with cytokine storm.

In the group of patients with cytokine storm, the diagnosis of "cytokine storm" was made by 3 clinical physicians (EFG, FD, ND) based on at least 3 consecutive tests that revealed increasingly high levels of CRP, ferritin, and D-dimer accompanied with increased fever and ongoing clinical deterioration.

CT images of the cases were drawn from our hospital's system of archived pictures and communications (PACS) and analyzed retrospectively. Cases that could not be evaluated due to artifacts like movement restriction, and those with structural abnormalities in the lung parenchyma, history of surgery, and detected mass were excluded from the study (OG, SUR). Finally, CT scans of 32 cases in the cytokine storm group and 36 cases in the non-cytokine storm group were included in the study.

All CT examinations were performed with MSCT device with 16 rows of detectors (Siemens Somatom Emotion 16, Siemens) using an automatic dose modulation technique and the same imaging protocol without administering intravenous contrast matter. The patients were instructed to hold their breath at the end of inspiration and were scanned in a supine position from the apex of the lung to the end of the costophrenic angle. The examination was performed with calibration set at $120 \mathrm{kVp}$, pitch at 1.35 , reconstruction matrix at $512 \times 512$, slice thickness at $1 \mathrm{~mm}$, and at high-spatial resolution algorithm. The images were evaluated in 3 planes using the multiplanar reformat (MPR) imaging technique.

\section{CT scoring}

The CT images obtained at the time of admission of all patients participating in the study were retrospectively evaluated by two radiologists with 10 and 12 years of experience, respectively, using the MPR images (Syngo Workstation Siemens / Germany) of the pulmonary parenchyma (WW: $1500 \mathrm{HU}, \mathrm{WL}:-500 \mathrm{HU}$ ). Before starting the study, 10 excluded cases were evaluated together by two radiologists in order to establish a consensus among investigators on the elementary pulmonary lesions that form the basis of CT scoring. The data that were agreed upon based on CT evaluations of each patient participating in the study were accepted as "final data," while in cases where the consensus could not be reached,

Tab. 1. CT score formulae.

\begin{tabular}{lllc}
\hline $\begin{array}{l}\text { Score } \\
\text { type }\end{array}$ & Definition & Formulization & $\begin{array}{c}\text { Min-max } \\
\text { score }\end{array}$ \\
\hline Score-1 & $\begin{array}{l}\text { Segment-based with } \\
\text { lesion distribution }\end{array}$ & $\begin{array}{l}\text { Percentage of involvement }(0-2) \times \text { involvement } \\
\text { characteristic }(0.2-1) \times \text { lesion distribution }(0.3-1)\end{array}$ & $0-40$ \\
\hline Score-2 & $\begin{array}{l}\text { Lobe-based with } \\
\text { lesion distribution }\end{array}$ & $\begin{array}{l}\text { Percentage of involvement }(0-5) \times \text { involvement } \\
\text { characteristic }(0.2-1) \times \text { lesion distribution }(0.3-1)\end{array}$ & $0-25$ \\
\hline Score-3 & $\begin{array}{l}\text { Segment-based without } \\
\text { lesion distribution }\end{array}$ & $\begin{array}{l}\text { Percentage of involvement }(0-2) \times \text { involvement } \\
\text { characteristic }(0.2-1)\end{array}$ & $0-40$ \\
\hline Score-4 & $\begin{array}{l}\text { Lobe-based without 1 } \\
\text { esion distribution }\end{array}$ & $\begin{array}{l}\text { Percentage of involvement }(0-5) \times \text { involvement } \\
\text { characteristic }(0.2-1)\end{array}$ & $0-25$ \\
\hline
\end{tabular}


Tab. 2. Baseline characteristics and computed tomography findings of all patients with confirmed COVID-19 pneumonia according to the presence/absence of cytokine storm.

\begin{tabular}{|c|c|c|c|}
\hline Variables & Absence of cytokine storm (n: 36) & Presence of cytokine storm (n: 32) & $\mathbf{p}$ \\
\hline \multicolumn{4}{|l|}{ Sex $n(\%)$} \\
\hline Male & $16(44.4)$ & $24(75)$ & 0.01 \\
\hline Age mean (SD) & $54.7(12.9)$ & $61.6(13.6)$ & 0.04 \\
\hline \multicolumn{4}{|l|}{ Comorbidities } \\
\hline • Diabetes mellitus & $9(25)$ & $8(25)$ & one \\
\hline • Chronic hypertension & $17(42)$ & $12(37.5)$ & 0.4 \\
\hline - Chronic kidney disease & $2(5.6)$ & $1(3.1)$ & 0.6 \\
\hline - Asthma & $1(2.8)$ & $5(15.6)$ & 0.09 \\
\hline - Pulmonary thromboembolism & $0(0)$ & $1(3.2)$ & 0.4 \\
\hline - Autoimmune disease & $0(0)$ & $1(3.2)$ & 0.4 \\
\hline • Malignancy & $0(0)$ & $1(3.2)$ & 0.4 \\
\hline At least one-comorbidity & $19(52.8)$ & $18(56.3)$ & 0.7 \\
\hline At least two comorbidities & $10(27.8)$ & $8(25)$ & 0.7 \\
\hline \multicolumn{4}{|c|}{ Laboratory findings on admission median (IQR 25-75\%) } \\
\hline - Leucocyte & $4950(4100$ to 6425$)$ & $6900(4700$ to 11600$)$ & 0.019 \\
\hline - Ferritin & $106(38$ to 225$)$ & $916(600$ to 1586$)$ & $<0.001$ \\
\hline - Lactate dehydrogenase & $228(204$ to 267$)$ & $458(340$ to 600$)$ & $<0.001$ \\
\hline - D-dimer & $455(307$ to 725$)$ & $1390(600$ to 2400$)$ & $<0.001$ \\
\hline - C-reactive protein & $12.5(4$ to 27.9$)$ & $205(149$ to 316$)$ & $<0.001$ \\
\hline - Fibrinogen & $358(300$ to 419$)$ & $668(593$ to 802$)$ & $<0.001$ \\
\hline \multicolumn{4}{|c|}{ Abnormality location and types on chest computed tomography images n (\%) } \\
\hline \multicolumn{4}{|c|}{ A1 LOBE } \\
\hline Negative & $12(33.3)$ & $3(9.4)$ & 0.017 \\
\hline Positive & $24(77.7)$ & $29(90.6)$ & \\
\hline \multicolumn{4}{|l|}{ Involvement percentage $\mathrm{n}(\%)$} \\
\hline - No involvement & $12(33.3)$ & $3(9.4)$ & \\
\hline$\cdot<5 \%$ & $7(19.4)$ & $2(6.3)$ & \\
\hline - $5-25 \%$ & $10(27.8)$ & $10(31.3)$ & \\
\hline$\cdot 25-50 \%$ & $3(8.3)$ & $9(28.1)$ & \\
\hline • $50-75 \%$ & $3(8.3)$ & $7(21.9)$ & \\
\hline$\cdot>75 \%$ & $1(2.8)$ & $1(3.1)$ & \\
\hline \multicolumn{4}{|l|}{ Involvement type } \\
\hline - Ground-glass opacity (GGO) & $17(47.2)$ & $6(18.8)$ & \\
\hline - Crazy-paving & $0(0)$ & $6(18.8)$ & \\
\hline - Consolidation & $1(2.8)$ & $2(6.3)$ & \\
\hline - GGO weighted mix consolidation $>50 \%$ & $6(16.7)$ & $15(46.9)$ & \\
\hline \multicolumn{4}{|l|}{ Lesion type } \\
\hline - Peripheral & $15(41.7)$ & $14(43.8)$ & \\
\hline • Random & $7(19.4)$ & $8(25)$ & \\
\hline - Diffuse & $2(5.6)$ & $7(21.9)$ & \\
\hline \multicolumn{4}{|l|}{ A2 LOBE } \\
\hline Negative & $14(38.9)$ & $5(15.6)$ & 0.032 \\
\hline Positive & $22(61.1)$ & $27(84.4)$ & \\
\hline \multicolumn{4}{|l|}{ Involvement percentage $\mathrm{n}(\%)$} \\
\hline - No involvement & $14(38.9)$ & $5(15.6)$ & \\
\hline - $<5 \%$ & $9(25)$ & $3(9.4)$ & \\
\hline$\cdot 5-25 \%$ & $7(19.4)$ & $13(40.6)$ & \\
\hline - $25-50 \%$ & $3(8.3)$ & $7(21.9)$ & \\
\hline - $50-75 \%$ & $3(8.3)$ & $3(9.4)$ & \\
\hline$\cdot>75 \%$ & $0(0)$ & $1(3.1)$ & \\
\hline \multicolumn{4}{|l|}{ Involvement type } \\
\hline - GGO & $15(41.7)$ & $7(21.9)$ & \\
\hline - Crazy-paving & $1(2.8)$ & $6(18.8)$ & \\
\hline - Consolidation & $3(8.3)$ & $1(3.1)$ & \\
\hline - GGO weighted mix consolidation $>50 \%$ & $3(8.3)$ & $13(40.6)$ & \\
\hline \multicolumn{4}{|l|}{ Lesion type } \\
\hline - Peripheral & $10(27.8)$ & $8(25)$ & \\
\hline - Random & $11(30.6)$ & $14(43.8)$ & \\
\hline - Diffuse & $1(2.8)$ & $5(15.6)$ & \\
\hline
\end{tabular}




\begin{tabular}{|c|c|c|c|}
\hline Variables & Absence of cytokine storm (n: 36) & Presence of cytokine storm (n: 32) & $\mathbf{p}$ \\
\hline \multicolumn{4}{|l|}{ A3 LOBE } \\
\hline Negative & $7(19.4)$ & $2(6.3)$ & 0.06 \\
\hline Positive & $29(80.6)$ & $30(93.7)$ & \\
\hline $\begin{array}{l}\text { Involvement percentage n (\%) } \\
\cdot \text { No involvement } \\
\cdot<5 \% \\
\cdot 5-25 \% \\
\cdot 25-50 \% \\
\cdot 50-75 \% \\
\cdot>75 \% \\
\end{array}$ & $\begin{array}{c}7(19.4) \\
9(25) \\
12(33.3) \\
4(11.1) \\
3(8.3) \\
1(2.8) \\
\end{array}$ & $\begin{array}{c}2(6.3) \\
2(6.3) \\
10(31.3) \\
10(31.3) \\
6(18.8) \\
2(6.3) \\
\end{array}$ & \\
\hline $\begin{array}{l}\text { Involvement type } \\
\text { - GGO } \\
\text { - Crazy-paving } \\
\text { - Consolidation } \\
\text { - GGO weighted mix consolidation }>50 \% \\
\end{array}$ & $\begin{array}{c}10(27.8) \\
4(11.1) \\
5(13.9) \\
10(27.8) \\
\end{array}$ & $\begin{array}{c}5(15.6) \\
1(3.1) \\
7(21.9) \\
17(53.1) \\
\end{array}$ & \\
\hline $\begin{array}{l}\text { Lesion type } \\
\text { - Peripheral } \\
\text { - Random } \\
\text { - Diffuse } \\
\end{array}$ & $\begin{array}{l}19(52.8) \\
7(19.4) \\
3(8.3)\end{array}$ & $\begin{array}{c}16(50) \\
10(31.3) \\
4(12.5)\end{array}$ & \\
\hline \multicolumn{4}{|l|}{ B1 LOBE } \\
\hline Negative & $11(30.6)$ & $2(6.3)$ & 0.01 \\
\hline Positive & $25(69.4)$ & $30(93.7)$ & \\
\hline $\begin{array}{l}\text { Involvement percentage n (\%) } \\
\cdot \text { No involvement } \\
\cdot<5 \% \\
\cdot 5-25 \% \\
\cdot 25-50 \% \\
\cdot 5075 \% \\
\cdot>75 \% \\
\end{array}$ & $\begin{array}{l}11(30.6) \\
11(30.6) \\
7(19.4) \\
4(11.1) \\
2(5.6) \\
1(2.8) \\
\end{array}$ & $\begin{array}{c}2(6.3) \\
0(0) \\
16(50) \\
12(37.5) \\
2(6.3) \\
0(0) \\
\end{array}$ & \\
\hline $\begin{array}{l}\text { Involvement type } \\
\text { - GGO } \\
\text { - Crazy-paving } \\
\text { - Consolidation } \\
\text { - GGO weighted mix consolidation }>50 \% \\
\end{array}$ & $\begin{array}{c}13(36.1) \\
3(8.3) \\
5(13.9) \\
4(11.1) \\
\end{array}$ & $\begin{array}{c}9(28.1) \\
2(6.3) \\
2(6.3) \\
17(53.1) \\
\end{array}$ & \\
\hline $\begin{array}{l}\text { Lesion type } \\
\text { - Peripheral } \\
\text { - Random } \\
\text { - Diffuse } \\
\end{array}$ & $\begin{array}{l}16(44.4) \\
6(16.7) \\
2(5.6) \\
\end{array}$ & $\begin{array}{c}14(43.8) \\
13(40.6) \\
3(9.4) \\
\end{array}$ & \\
\hline \multicolumn{4}{|l|}{ B2 LOBE } \\
\hline $\begin{array}{l}\text { Negative } \\
\text { Positive } \\
\end{array}$ & $\begin{array}{c}8(22.2) \\
28(77.8)\end{array}$ & $\begin{array}{c}2(6.3) \\
30(93.7)\end{array}$ & 0.06 \\
\hline $\begin{array}{l}\text { Involvement percentage n (\%) } \\
\text { - No involvement } \\
\cdot<5 \% \\
\cdot 5-25 \% \\
\cdot 25-50 \% \\
\cdot 50-75 \% \\
\text { - }>75 \% \\
\end{array}$ & $\begin{array}{c}8(22.2) \\
8(22.2) \\
17(47.2) \\
1(2.8) \\
0(0) \\
2(5.6) \\
\end{array}$ & $\begin{array}{c}2(6.3) \\
3(9.4) \\
13(40.6) \\
7(21.9) \\
4(12.5) \\
3(9.4) \\
\end{array}$ & \\
\hline $\begin{array}{l}\text { Involvement type } \\
\text { - GGO } \\
\text { - Crazy-paving } \\
\text { - Consolidation } \\
\text { - GGO weighted mix consolidation }>50 \% \\
\end{array}$ & $\begin{aligned} & 11(30.6) \\
& 1(2.8) \\
& 10(27.8) \\
& 6(16.7) \\
&\end{aligned}$ & $\begin{array}{c}5(15.6) \\
1(3.1) \\
9(28.1) \\
15(46.9) \\
\end{array}$ & \\
\hline $\begin{array}{l}\text { Lesion type } \\
\text { - Peripheral } \\
\text { - Random } \\
\text { - Diffuse } \\
\end{array}$ & $\begin{array}{c}22(61.1) \\
4(11.1) \\
2(5.6)\end{array}$ & $\begin{array}{l}16(50) \\
8(25) \\
6(18.8)\end{array}$ & \\
\hline \multicolumn{4}{|l|}{ Final computed tomography scores } \\
\hline $\begin{array}{l}\text { Score } 1 \\
\text { Score } 2 \\
\text { Score } 3 \\
\text { Score } 4\end{array}$ & $\begin{array}{l}3.63(1.19 \text { to } 7.81) \\
0.96(0.31 \text { to } 2.37) \\
6.1(2.8 \text { to } 14) \\
2.8(1 \text { to } 5.2)\end{array}$ & $\begin{array}{c}13.4(7.12 \text { to } 19.3) \\
4.2(2.1 \text { to } 7.7) \\
19.5(10.3 \text { to } 27.4) \\
8.4(5.4 \text { to } 13.2)\end{array}$ & $\begin{array}{l}<0.001 \\
<0.001 \\
<0.001 \\
<0.001\end{array}$ \\
\hline
\end{tabular}

GGO: Ground-glass opacity, Score 1: segment-based with lesion distribution, Score 2: lobe-based with lesion distribution, Score 3: segment-based without lesion distribution, Score 4: lobe-based without lesion distribution 
the decision was made by a third radiologist (with 20 years of experience) and that was accepted as the final decision.

Four CT scoring formulas were created for CT scoring. Among these, two included the signs of lung parenchymal involvement (type of elementary lesion), lesion distribution characteristics, and amount of segment- or lobe-specific involvement (scores 1 and 2 , respectively). The other two scores were created by excluding the lesion distribution characteristics from the above-mentioned parameters (scores 3 and 4, respectively).

1. Characteristics of elementary lesions in the lung parenchyma were referred to as ground glass density, crazy paving pattern, consolidation and ground glass, and mix consolidation (combination of crazy paving pattern and consolidation) in accordance with the definitions in the Fleischner Society's glossary (8). These elementary lesions were included in the formula by giving them coefficients gradually increasing from ground glass to consolidation according to their radiological severity (ground glass opacity: 0.2 , crazy paving pattern: 0.5 , mix consolidation: 0.8 , pure consolidation: 1 ).

2. The distribution of lesions was referred to as "peripheral" (peripheral involvement in one-third of the lung parenchyma), "random" (not presenting peripheral or central dominance), "diffuse" (diffuse involvement regardless of segments), and these involvement patterns were included in the formula by means of their coefficients (peripheral: 0.3, random: 0.6, diffuse: 1).

3. Lobar and segmental evaluation was performed to determine the rate of involvement:

a. Involvement rate in segmental scoring. In total, 18 lung segments in two lungs were divided into 20 regions (left apicoposterior segment was divided into apical and posterior regions and left anteromedial basal segment into anterior and mediobasal regions). The involvement rates were evaluated separately for each region (no involvement: 0 , involvement of $<50 \%$ : 1 , involvement of $>50 \%: 2$ ).

b. Involvement rate in lobar scoring. The lung parenchyma of five anatomical lobes was evaluated as described by Pan et al (7). The involvement rates were evaluated separately for each lobe (no involvement: 0 , involvement of $<5 \%$ : 1 , involvement of 5-25\%: 2, involvement of 26-49\%: 3, involvement of 50-75\%: 4, involvement of > $75 \%: 5$ ).

Four scoring formulas were created as shown in Table 1.

In addition, the comorbidity characteristics (diabetes mellitus, hypertension, autoimmune disease, cancer, renal dysfunction, etc.) of the patients who underwent $\mathrm{CT}$ imaging were recorded from their files.

\section{Statistical analyses}

All data were analyzed by IBM SPSS Statistics for Mac, version 25.0 for Mac OS X (IBM Corp., Armonk, NY, USA). The normality of the data distribution was determined by the ShapiroWilk test, histograms, and QQ plots. The categorical values of the patients expressed as numbers and percentages were analyzed with a Chi-squared test. Continuous values were presented as mean and standard deviation (SD) or median values and an interquartile range (IQR) of 25-75\%. The non-parametric values were

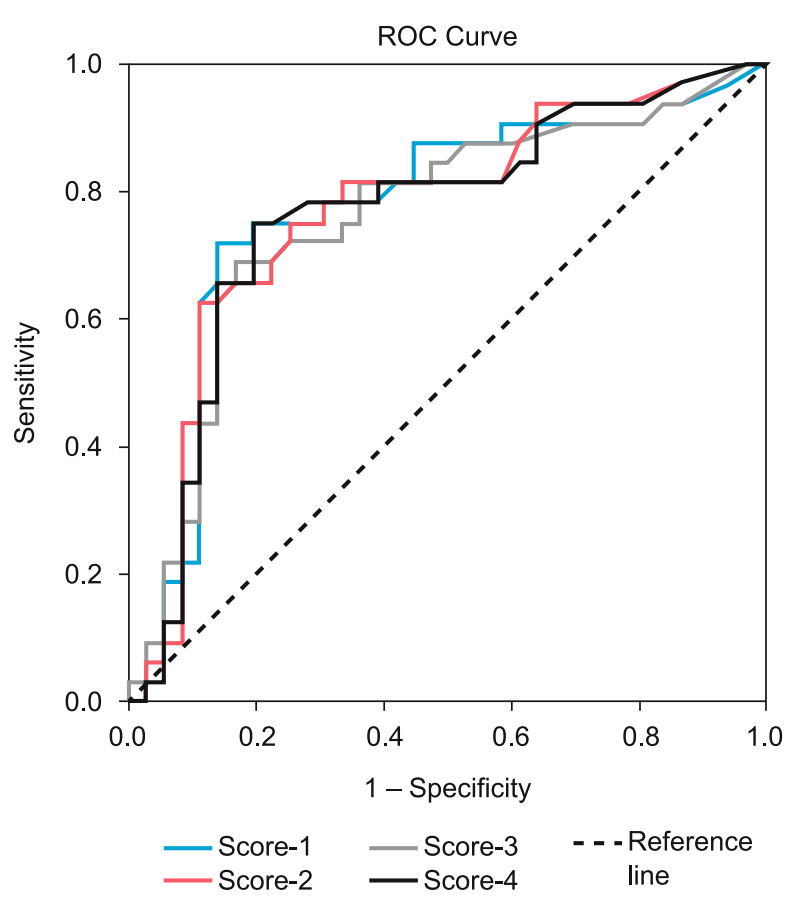

Fig. 2. ROC analysis results

analyzed using Mann-Whitney $U$ test, and the parametric ones with student-t test. To assess the prognostic utility of CT scores at varying cut-off values for the prediction of patients with cytokine storm, a receiver-operating characteristic (ROC) curve was generated, and the area under the curve (AUC) was calculated. The best of the cut-off values was decided using Youden's Index. To determine the predictive value of several variables, a multivariate regression model (with block-wise entry hierarchical method) was created using variables whose $p$ value was $<0.25$ in univariate analyses. The presence of correlation among these variables was analyzed using Spearman test, and in each pair, the variable with a detected correlation with another variable was excluded from the regression model. To assess the model's goodness of fit, the Hosmer-Lemeshow test was performed. The $95 \%$ confidence intervals (95\% CIs) were calculated whenever appropriate, and a two-tailed $\mathrm{p}$ value $<0.05$ was considered statistically significant.

\section{Results}

During the study period, 68 patients with the diagnosis of COVID-19 pneumonia confirmed by PCR test and chest CT images were enrolled in this study. The mean age of patients was 57.72 (SD: 13.5$)$, and 40 (58.8\%) of them were male. Among all the patients, $32(47.1 \%)$ were diagnosed with cytokine storm and the remaining $36(52.9 \%)$ were assigned to the non-cytokine-storm group (Tab. 2). Cytokine storm was significantly more common among male patients and patients of older age $(\mathrm{p}=0.04)$. Diffuse lesion distribution was observed to be more common in cases included in the cytokine storm group as compared to the control group ( $n=11, n=4$, respectively). When the lung involvement area 
Tab. 3. The prognostic values of all computed tomography scores for predicting cytokine storm in patients with the diagnosis of COVID-19 pneumonia.

\begin{tabular}{|c|c|c|c|c|c|}
\hline Variables & & Score 1 & Score 2 & Score 3 & Score 4 \\
\hline \multirow{3}{*}{$\operatorname{AUC}(95 \% \mathrm{CI})$} & For all patients & $0.772(0.651$ to 0.892$)$ & $0.766(0.647$ to 0.885$)$ & $0.758(0.639$ to 0.878$)$ & $0.760(0.640$ to 0.881$)$ \\
\hline & For males & $0.781(0.631$ to 0.932$)$ & $0.781(0.628$ to 0.934$)$ & $0.786(0.638$ to 0.935$)$ & 0.805 (0.656 to 0.953$)$ \\
\hline & For females & $0.700(0.447$ to 0.952$) * *$ & $0.709(0.482$ to 0.936$) * *$ & $0.656(0.407$ to 0.905$) * *$ & $0.678(0.452$ to 0.904$) * *$ \\
\hline \multirow{3}{*}{ Best cut-off value* } & For all patients & 10.04 & 3.18 & 15.7 & 6 \\
\hline & For males & 10.19 & 3.18 & 15.7 & 7.4 \\
\hline & For females & $\mathrm{N} / \mathrm{A}$ & $\mathrm{N} / \mathrm{A}$ & $\mathrm{N} / \mathrm{A}$ & $\mathrm{N} / \mathrm{A}$ \\
\hline \multirow{3}{*}{ Sensitivity $(95 \% \mathrm{CI})$} & For all patients & $71.8(53.2$ to 86.2$)$ & $65.6(46.8$ to 81.4$)$ & $68.75(49.99$ to 83.88$)$ & $75(56.6$ to 88.54$)$ \\
\hline & For males & $70.8(48.9$ to 87.3$)$ & $66.7(44.6$ to 84.3$)$ & $75(53.2$ to 90.2$)$ & $75(53.2$ to 90.2$)$ \\
\hline & For females & $\mathrm{N} / \mathrm{A}$ & $\mathrm{N} / \mathrm{A}$ & $\mathrm{N} / \mathrm{A}$ & $\mathrm{N} / \mathrm{A}$ \\
\hline \multirow{3}{*}{ Specificity $(95 \% \mathrm{CI})$} & For all patients & 86.1 (70.5 to 95.3$)$ & 86.1 (70.5 to 95.3) & $83.33(67.19$ to 93.63$)$ & $80.56(63.98$ to 91.81$)$ \\
\hline & For males & 87.5 (61.6 to 98.4$)$ & 93.7 (69.7 to 99.8$)$ & 87.5 (61.6 to 98.4$)$ & 93.7 (69.7 to 99.8$)$ \\
\hline & For females & $\mathrm{N} / \mathrm{A}$ & $\mathrm{N} / \mathrm{A}$ & $\mathrm{N} / \mathrm{A}$ & $\mathrm{N} / \mathrm{A}$ \\
\hline \multirow{3}{*}{$\operatorname{PLR}(95 \% \mathrm{CI})$} & For all patients & $5.18(2.23$ to 12$)$ & $4.73(2.02$ to 11.08$)$ & $4.13(1.92$ to 8.89$)$ & $3.86(1.93$ to 7.73$)$ \\
\hline & For males & $5.67(1.51$ to 21.2$)$ & $10.67(1.57$ to 72.6$)$ & $6(1.61$ to 22.3$)$ & $12(1.77$ to 81.8$)$ \\
\hline & For females & $\mathrm{N} / \mathrm{A}$ & $\mathrm{N} / \mathrm{A}$ & $\mathrm{N} / \mathrm{A}$ & $\mathrm{N} / \mathrm{A}$ \\
\hline \multirow{3}{*}{ NLR $(95 \%$ CI $)$} & For all patients & $0.33(0.19$ to 0.58$)$ & $0.4(0.24$ to 0.66$)$ & $0.38(0.22$ to 0.65$)$ & $0.31(0.17$ to 0.58$)$ \\
\hline & For males & $0.33(0.17$ to 0.63$)$ & $0.36(0.2$ to 0.64$)$ & $0.29(0.14$ to 0.59$)$ & $0.27(0.13$ to 0.55$)$ \\
\hline & For females & $\mathrm{N} / \mathrm{A}$ & $\mathrm{N} / \mathrm{A}$ & $\mathrm{N} / \mathrm{A}$ & $\mathrm{N} / \mathrm{A}$ \\
\hline \multirow{3}{*}{ Accuracy $(95 \% \mathrm{CI})$} & For all patients & 79.4 (67.8 to 88.2$)$ & 76.4 (64.6 to 85.9) & $76.47(64.62$ to 85.91$)$ & $77.94(66.24$ to 87.1$)$ \\
\hline & For males & $77.5(61.5$ to 89.1$)$ & $77.5(61.5$ to 89.1$)$ & $80(64.3$ to 90.9$)$ & $82.5(67.2$ to 92.6$)$ \\
\hline & For females & $\mathrm{N} / \mathrm{A}$ & $\mathrm{N} / \mathrm{A}$ & $\mathrm{N} / \mathrm{A}$ & $\mathrm{N} / \mathrm{A}$ \\
\hline
\end{tabular}

* The best of cut-off values was decided by using Youden's Index. ** It was not statistically significant, i.e., $\mathrm{p}$ values $>0.05$.

95\% CI: 95\% confidence interval; AUC: area under curve; PLR: positive likelihood ratio; NLR: negative likelihood ratio; N / A: not applicable, not found statistically significant in ROC analysis.

Tab. 4. Multivariate logistic regression for predicting cytokine storm in patients with COVID-19 pneumonia.

\begin{tabular}{|c|c|c|c|c|c|}
\hline & $\begin{array}{l}\text { Absence cytokine } \\
\text { storm (n: } 36)\end{array}$ & $\begin{array}{l}\text { Presence cytokine } \\
\text { storm (n: } 32)\end{array}$ & $\mathrm{p}$ & $\begin{array}{l}\text { Unadjusted odds } \\
\text { ratio } 95 \% \mathrm{CI}\end{array}$ & $\begin{array}{l}\text { Adjusted odds } \\
\text { ratio } 95 \% \mathrm{CI}\end{array}$ \\
\hline \multicolumn{6}{|l|}{ Gender n (\%) } \\
\hline • Male & $16(44.4)$ & $24(75)$ & 0.01 & $3.75(1.31$ to 10.5$)$ & 3.57 (1.09 to 11.6$)$ \\
\hline Age Median (IQR25-75\%) & $54.7(12.9)$ & $61.6(13.6)$ & 0.04 & $1.039(0.99$ to 1.080$)$ & $1.039(0.994$ to 1.086$)$ \\
\hline \multicolumn{6}{|l|}{ Comorbidities n (\%) } \\
\hline • Diabetic mellitus & $9(25)$ & $8(25)$ & 1 & $1(0.33$ to 3.003$)$ & $\mathrm{N} / \mathrm{I}^{\mathrm{b}}$ \\
\hline • Chronic hypertension & $17(42)$ & $12(37.5)$ & 0.4 & $0.6(0.25$ to 1.76$)$ & $\mathrm{N} / \mathrm{I}^{\mathrm{b}}$ \\
\hline - Chronic kidney diseases & $2(5.6)$ & $1(3.1)$ & 0.6 & $0.54(0.47$ to 6.3$)$ & $\mathrm{N} / \mathrm{I}^{\mathrm{b}}$ \\
\hline - Asthma & $1(2.8)$ & $5(15.6)$ & 0.09 & $6.4(0.71$ to 58.7$)$ & $\mathrm{N} / \mathrm{I}^{\mathrm{a}}$ \\
\hline - Pulmonary thromboembolism & $0(0)$ & $1(3.2)$ & 0.4 & $\mathrm{~N} / \mathrm{A}^{\mathrm{a}}$ & $\mathrm{N} / \mathrm{I}^{\mathrm{b}}$ \\
\hline - Auto-immune diseases & $0(0)$ & $1(3.2)$ & 0.4 & $\mathrm{~N} / \mathrm{A}^{\mathrm{a}}$ & $\mathrm{N} / \mathrm{I}^{\mathrm{b}}$ \\
\hline • Malignity & $0(0)$ & $1(3.2)$ & 0.4 & $\mathrm{~N} / \mathrm{A}^{\mathrm{a}}$ & $\mathrm{N} / \mathrm{I}^{\mathrm{b}}$ \\
\hline At least one comorbidity $\mathrm{n}(\%)$ & $19(52.8)$ & $18(56.3)$ & 0.7 & $1.15(0.44$ to 2.96$)$ & $\mathrm{N} / \mathrm{I}^{\mathrm{b}}$ \\
\hline At least two comorbidities n (\%) & $10(27.8)$ & $8(25)$ & 0.7 & $1.15(0.39$ to 3.4$)$ & $\mathrm{N} / \mathrm{I}^{\mathrm{b}}$ \\
\hline CT Score Median (IQR25-75\%) & $2.8(1$ to 5.2$)$ & $8.4(5.4$ to 13.2$)$ & $<0.001$ & $1.2(1.07$ to 1.34$)$ & $1.16(1.038$ to 1.309$)$ \\
\hline A1 lob involvement $\mathrm{n}(\%)$ & $24(77.7)$ & $29(90.6)$ & 0.017 & $4.83(1.22$ to 19.1$)$ & $\mathrm{N} / \mathrm{A}^{\mathrm{c}}$ \\
\hline A2 lob involvement n (\%) & $22(61.1)$ & $27(84.4)$ & 0.032 & $3.43(1.07$ to 11.02$)$ & $\mathrm{N} / \mathrm{A}^{\mathrm{c}}$ \\
\hline A3 lob involvement n (\%) & $29(80.6)$ & $30(93.7)$ & 0.06 & $3.6(0.6$ to 18.8$)$ & $\mathrm{N} / \mathrm{A}^{\mathrm{c}}$ \\
\hline B1 lob involvement n (\%) & $25(69.4)$ & $30(93.7)$ & 0.01 & $6.6(1.3$ to 32.6$)$ & $\mathrm{N} / \mathrm{A}^{\mathrm{c}}$ \\
\hline B2 lob involvement $\mathrm{n}(\%)$ & $28(77.8)$ & $30(93.7)$ & 0.06 & $4.2(0.8$ to 21.9$)$ & $\mathrm{N} / \mathrm{A}^{\mathrm{c}}$ \\
\hline
\end{tabular}

N/A: not applicable; N/I: not included

a - Insufficient sample size in cells for performing regression analysis

$\mathrm{b}-\mathrm{p}$ values were higher than 0.25 . Therefore, it was not included in the regression model.

c - All parameters were highly correlated with each other

was examined, the involvement in the upper zones of both lungs and in the middle lobe of the right lung was significantly higher in the cytokine storm group as compared to the non-cytokine-storm group (Tab. 1). All the CT findings and scores are presented in Table 2. On comparing CT findings and CT scores of both groups, it was found that all CT score points were higher in patients with cytokine storm than in those without cytokine storm $(\mathrm{p}<0.001)$ (Tab. 2).

To assess the prognostic utility of all CT scores at varying cutoff values for predicting the cytokine storm, an ROC curve was generated, and AUC was calculated. Accordingly, the AUC values of CT score $1, \mathrm{CT}$ score $2, \mathrm{CT}$ score 3 , and CT score 4 were as fol- 
lows; 0.772 (95\% CI; 0.651-0.892), 0.766 (95\% CI; 0.647-0.885), 0.758 (95\% CI; 0.639-8.78), and 0.760 (95\% CI; 0.640-0.881), respectively (Fig. 2). All CT scores had better predictive values in males (Tab. 3). The best cut-off value of all CT scores for predicting the cytokine storm, and the sensitivity / specificity values pertaining to this cut-off level are presented in Table 3.

The regression analysis results are presented in Table 4 .

\section{Discussion}

Cytokine storm is a life-threatening critical condition that requires intensive care and has a very high mortality rate (1). Early recognition and prompt treatment provide better clinical outcomes (1). Numerous studies have reported that CT scoring calculated by both qualitative and quantitative methods can predict a clinically severe disease at varying degrees of reliability (7, 9-11). In this study, we investigated whether CT findings at admission can be used to predict cases in which cytokine storm will develop. Unlike many CT scoring studies in the literature, along with the extent of lesion, we also included elementary lesions of lung involvement and lesion distribution pattern into our scoring system. In the scoring we obtained, it was observed that among all male patients the CT score was significantly higher in the cytokine storm group; however, this difference was not detected in female patients. Further, it was observed that the incorporation of the lesion distribution pattern into the CT scoring formula (scores 1 and 2) to predict cytokine storm did not create a significant difference in the accuracy and reliability values of the CT scoring. Since there is no significant difference in predicting the cytokine storm among all four CT scoring methods we have created, we believe that the "lobe-based CT score without lesion distribution" (score 4) can provide information with similar levels of high sensitivity and specificity (Tab. 3) more practically as it can be applied in a shorter period.

In the literature, there are studies showing that the dominant lesion is that of ground-glass opacity in patients with mild disease, and consolidation or mix consolidation in patients with severe disease $(12,13)$. In another study, it was concluded that, contrary to the previous literature, ARDS developing as a result of COVID-19 infection cannot be predicted alone by the rate of involvement detected on CT, and that lesion density and localization are parameters effective in predicting the risk of ARDS development (10). Hence, we believe that in addition to the score for the rate of lesion involvement detected with CT, the scoring should include also the characteristics of the elementary lesion, and this information strongly contributed to devising the scoring formulas we created. Thus, we believe that it will help the clinicians in recognizing the cases that are likely to develop a cytokine storm.

In studies comparing severe and mild cases of the disease, the severe cases have been shown to have higher numbers of segments involved and larger opacities (13). Liu et al tried to predict the severity of the disease by measuring the volumes of ground glass opacity, semi-consolidation, and consolidation with the help of software, and concluded that CT features at the time of admission could predict severity of the disease [AUC; 0.76
(0.66-0.86)]. They also showed that CT features have a better predictive value when age and sex parameters are added into their analysis (14). In another study investigating the predictive value of CT score as to mortality and disease severity, the parameter of age and high CT score were shown to be independent predictors of death and severity of the disease (6). In a study by Yu et al, multivariate logistic regression analysis showed that the lung severity score calculated by age, lesion density, and involvement rate were independent predictors for predicting the severity of the disease, while the presence of accompanying comorbidity was not a predictive factor (15). In our study, the score detected from admission CT was higher in the males and elderly included in the cytokinestorm group. Similarly, in a multivariate logistic regression analysis, it was shown that the CT score could independently predict the cytokine storm by age and male sex (Tab. 4), and the presence of comorbidity in our study cohort did not contribute to the prediction of cytokine storm.

There are studies showing that involvement of some zones or lobes in the lung may pose a risk for disease progression or poor prognosis (10). In our study, in the univariate analysis, the OR of the upper lobes in both lungs and the middle-lobe involvement in the right lung was significantly higher in predicting the cytokine storm (Tab. 4).

It has been shown in many studies that the lesions in COVID-19 pneumonia classically show a more peripheral distribution $(7,9)$. In the literature, there are data showing that the central or diffuse distribution is more common in cases with a severe prognosis (15). Therefore, we believed that the distribution characteristic on admission $\mathrm{CT}$ might change the predictive value of the CT score. In our study, the diffuse lesion distribution was seen to be more common at the time of admission in the cytokine storm group (n: 11/4 cases); however, the lesion distribution characteristic added to the total CT score did not significantly contribute to the CT score's accuracy. Therefore, we believe that the lesion distribution is not necessarily needed as a parameter in CT scoring.

Our study has some limitations. Firstly, although clinical and some laboratory values are currently widely used in the diagnosis of cytokine storm, including proinflammatory mediators such as interleukin IL-2, IL-6 etc., in a situation where the resources of the health system are strained worldwide, the proinflammatory cytokines could not be examined in our hospital just as in many other places. Therefore, the use of CT findings in predicting the cytokine storm can be a practical solution to the diagnosis.

Secondly, although in some studies, dynamic changes in early sequential CTs were shown to be useful in predicting the disease severity, the follow-up CTs could not be obtained in all patients; thus, long-term changes from day 0 could not be evaluated. However, we believe that it is more valuable to be able to provide foresight with as little logistics, intervention, and data as possible in the situation of the current pandemic which pushes the limits of our health systems.

Thirdly, since our study focuses on early detection of cases in which cytokine storm is likely to develop, the relationship of CT scoring with total survival time and mortality was not included in the study. 
405-412

To conclude, we believe that the use of "lobe-based CT score without lesion distribution" (score 4) can provide similar but more practical information with high accuracy/specificity for cytokine storm prediction, given the lack of significant differences among our CT scores in predicting the cytokine storm. Therefore, this suggests that lesion distribution characteristics do not contribute to the solution. For this reason, we think that the use of the CT score 4 that we have created in all CT evaluations at the time of admission can be used to recognize cases that are likely to develop the cytokine storm later, and thus, it can contribute to a more efficient use of the health system by means of separating cases that may require a more intensive clinical surveillance and treatment.

\section{References}

1. Ragab D, Salah Eldin H, Taeimah M, Khattab R, Salem R. The COVID-19 Cytokine Storm; What We Know So Far. Frontiers Imunol 2020; 11: 1446.

2. Meftahi GH, Jangravi Z, Sahraei H, Bahari Z. The possible pathophysiology mechanism of cytokine storm in elderly adults with COVID-19 infection: the contribution of "inflame-aging". Inflammation Res 2020; 69 (9): 825-839.

3. Long C, Xu H, Shen Q, Zhang X, Fan B, Wang C et al. Diagnosis of the Coronavirus disease (COVID-19): rRT-PCR or CT? Eur J Radiol 2020; 126: 108961.

4. Fang Y, Zhang H, Xie J, Lin M, Ying L, Pang P et al. Sensitivity of Chest CT for COVID-19: Comparison to RT-PCR. Radiology 2020; 296 (2): E115-e117.

5. Li X, Geng M, Peng Y, Meng L, Lu S. Molecular immune pathogenesis and diagnosis of COVID-19. J Pharm Analysis 2020; 10 (2): 102-108.

6. Francone M, Iafrate F, Masci GM, Coco S, Cilia F, Manganaro L et al. Chest CT score in COVID-19 patients: correlation with disease severity and short-term prognosis. Eur Radiol 2020; 30 (12): 6808-6817.
7. Pan F, Ye T, Sun P, Gui S, Liang B, Li L et al. Time Course of Lung Changes at Chest CT during Recovery from Coronavirus Disease 2019 (COVID-19). Radiology 2020; 295 (3): 715-721.

8. Hansell DM, Bankier AA, MacMahon H, McLoud TC, Müller NL, Remy J. Fleischner Society: glossary of terms for thoracic imaging. Radiology 2008; 246 (3): 697-722.

9. Huang G, Gong T, Wang G, Wang J, Guo X, Cai E et al. Timely Diagnosis and Treatment Shortens the Time to Resolution of Coronavirus Disease (COVID-19) Pneumonia and Lowers the Highest and Last CT Scores From Sequential Chest CT. Amer J Roentgenol 2020; 215 (2): 367-373.

10. Wang Y, Chen Y, Wei Y, Li M, Zhang Y, Zhang N et al. Quantitative analysis of chest CT imaging findings with the risk of ARDS in COVID-19 patients: a preliminary study. Ann Translat Med 2020; 8 (9): 594.

11. Zhao W, Zhong Z, Xie X, Yu Q, Liu J. Relation Between Chest CT Findings and Clinical Conditions of Coronavirus Disease (COVID-19) Pneumonia: A Multicenter Study. Amer J Roentgenol 2020; 214 (5): 1072-1077.

12. Song F, Shi N, Shan F, Zhang Z, Shen J, Lu H et al. Emerging 2019 Novel Coronavirus (2019-nCoV) Pneumonia. Radiology 2020; 295 (1): 210-217.

13. Yu M, Xu D, Lan L, Tu M, Liao R, Cai S et al. Thin-section Chest CT Imaging of Coronavirus Disease 2019 Pneumonia: Comparison Between Patients with Mild and Severe Disease. Radiology: Cardiothoracic Imaging 2020; 2 (2): e200126.

14. Liu F, Zhang Q, Huang C, Shi C, Wang L, Shi $N$ et al. CT quantification of pneumonia lesions in early days predicts progression to severe illness in a cohort of COVID-19 patients. Theranostics 2020; 10 (12): $5613-5622$.

15. Yu Y, Wang X, Li M, Gu L, Xie Z, Gu W et al. Nomogram to identify severe coronavirus disease 2019 (COVID-19) based on initial clinical and CT characteristics: a multi-center study. BMC medical imaging 2020; 20 (1): 111. 